\title{
Review
}

\section{Autoimmune hepatitis and its variant syndromes}

Autoimmune hepatitis (AIH) is characterised by female predominance, interface hepatitis, hypergammaglobulinaemia, and autoantibodies. ${ }^{12}$ Typically, the disease responds well to corticosteroid therapy, and clinical, laboratory, and histological remission can be achieved in $65 \%$ of patients within 18 months. ${ }^{3}$ Among Caucasoid Northern Europeans, its mean annual incidence is 1.9 per 100000 , and its point prevalence is 16.9 per $100000 .^{5}$ In the USA, AIH affects $100000-200000$ individuals. ${ }^{6}$ It accounts for $2.6 \%$ of the liver transplants in the European Liver Transplant Registry $^{7}$ and $5.9 \%$ of liver transplants in the USA. ${ }^{8}$

\section{Classical autoimmune hepatitis}

Three types of AIH have been proposed based on immunoserological findings but only two types have mutually exclusive autoantibodies and different clinical profiles. ${ }^{9}$ Type $1 \mathrm{AIH}$ is the most common form of the disease worldwide and is associated with antinuclear antibodies (ANA) and/or smooth muscle antibodies (SMA). It affects all age groups and is associated with human leucocyte antigen (HLA) DR3 (DRB1*0301) and DR4 (DRB $\left.{ }^{\star}{ }^{\star} 0401\right)$ in Caucasoid Northern European and North American patients. ${ }^{10}{ }^{11} D R B 1{ }^{\star} 0301$ and $D R B 1{ }^{\star} 0401$ influence disease expression and behaviour as well as susceptibility. Caucasoid patients with type $1 \mathrm{AIH}$ and $\mathrm{DRB} 1^{\star} 0301$ are younger, and have a higher frequency of treatment failure, ${ }^{12}$ relapse after drug withdrawal, ${ }^{13}$ and requirement for liver transplantation than patients with other alleles. ${ }^{14}$ In contrast, patients with $D R B 1{ }^{\star} 0401$ are typically older, frequently have concurrent autoimmune diseases, and respond better to corticosteroids than counterparts with $D R B 1{ }^{\star} 0301 .^{15}$

Type 2 AIH affects mainly children and is characterised by antibodies to liver/kidney microsome type 1 (antiLKM1). ${ }^{16}$ The target autoantigen of type $2 \mathrm{AIH}$ is the cytochrome mono-oxygenase P450 IID6 (CYP2D6), ${ }^{17} 18$ and five antigenic sites located between peptides 193-212, 257-269, 321-351, 373-389, and 410-429 are recognised by anti-LKM1. ${ }^{19}{ }^{20}$ The main antigenic site is the peptide sequence 257-269 and the second most recognised sequence is $321-351$. Most patients with type $2 \mathrm{AIH}$ have anti-LKM1 that react against one of these short linear sequences, ${ }^{19}{ }^{20}$ and this reactivity distinguishes them from those patients with anti-LKM1 and chronic hepatitis C. ${ }^{21}{ }^{22}$ Susceptibility to type $2 \mathrm{AIH}$ appears to relate to $D R B 1^{\star} 0701,{ }^{23}{ }^{24}$ but HLA B14, DR3, and $C 4 A-Q O$ have also been incriminated. ${ }^{25}$ Immune diseases (especially vitiligo, autoimmune thyroiditis, and insulin dependent diabetes mellitus) and organ specific autoantibodies (antibodies to thyroid, parietal cell, and/or islets of Langerhans) occur commonly. ${ }^{16}$ Initial studies that suggested a poorer outcome in type 2 than in type $1 \mathrm{AIH}^{16}$ have not been substantiated, and both type 1 and type 2 disease respond comparably to corticosteroids. ${ }^{26}{ }^{27}$ Both types can have an acute, even fulminant, presentation, and prompt recognition and treatment are necessary to control inflammatory activity. ${ }^{28-30}$

$\mathrm{AIH}$ in association with anti-LKM1 has also been described in $15 \%$ of patients with autoimmune polyglandular syndrome type 1 (APS 1 ). ${ }^{31-33}$ This syndrome is caused by a single gene mutation located on chromosome 21q22.3. ${ }^{34}{ }^{35}$ The APS1 gene encodes for a transcription factor called the autoimmune regulator which is expressed in epithelial and dendritic cells within the thymus where it may regulate clonal deletion of autoreactive $\mathrm{T}$ cells and affect self tolerance. Ectodermal dystrophy, mucocutaneous candidiasis, multiple endocrine gland failure (parathyroids, adrenals, ovaries), autoantibody production, and $\mathrm{AIH}$ in various syndromatic combinations are features of the disease. ${ }^{36}$ Unlike other autoimmune diseases, APS1 has a mendelian pattern of inheritance, complete penetrance of the gene, no class II HLA associations, and no female predominance. The cytochromes CYP1A2 and CYP2A6 are the major hepatic autoantigens of APS1, and reactivities against these targets have distinguished patients with APS1 from those with type 2 AIH. ${ }^{36}{ }^{37}$ Recent studies however in patients with anti-LKM1, AIH, and associated endocrinopathies have blurred this distinction by indicating anti-LKM1 reactivity against P450 IID6 (CYP2D6). ${ }^{38}$

Type $3 \mathrm{AIH}$ is the least established form and has been characterised by antibodies to soluble liver antigen (anti-SLA). ${ }^{39}$ Recently, anti-SLA have been shown to be identical to antibodies to liver-pancreas (anti-LP), and the autoantibodies are now designated anti-SLA/LP. ${ }^{40-42}$ Reactivities to cytokeratins 8 and 18 were described initially, ${ }^{43}$ and then glutathione S-transferases were proposed as autoantigens. ${ }^{44}$ A $50 \mathrm{kDa}$ liver cytosolic protein is now considered the more likely target, ${ }^{45}$ and this antigen may be a transfer RNA complex involved in the incorporation of selenocysteine into polypeptide chains $\left(\mathrm{tRNP}{ }^{(\mathrm{Ser}) \mathrm{Sec}} \mathrm{com}-\right.$ plex) ${ }^{46}$ Antibodies to the $\mathrm{RNP}^{(\mathrm{Ser}) \mathrm{Sec}}$ complex have characterised patients with severe $\mathrm{AIH}$ and poor response to corticosteroids. ${ }^{47}$ Reactivity to conformational epitopes of the $50 \mathrm{kDa}$ tRNA associated antigenic protein has been demonstrated in patients with type $1 \mathrm{AIH}$, type $2 \mathrm{AIH}$, and ANA/SMA positive sclerosing cholangitis. ${ }^{48}$ Patients with anti-SLA/LP have clinical and laboratory features that are indistinguishable from patients with type $1 \mathrm{AIH}$ and they respond well to corticosteroids. ${ }^{42}{ }^{49}$ The evolving experience with anti-SLA/LP indicates that they are additional markers of autoimmune hepatitis rather than hallmarks of a separate entity. Indeed, the original promoters of a type 3 AIH have had serious doubts about its existence. ${ }^{4}$ The major clinical value of testing for anti-SLA/LP may be in the reclassification of patients with cryptogenic chronic hepatitis. $^{42} 49$

\section{Diagnostic criteria}

The diagnostic criteria for AIH have been codified and updated by an international panel. ${ }^{50}{ }^{51} \mathrm{~A}$ definite diagnosis requires exclusion of viral, drug induced, alcoholic, and

Abbreviations used in this paper: $\mathrm{AIH}$, autoimmune hepatitis; AIC, autoimmune cholangitis; ANA, antinuclear antibodies; SMA, smooth muscle antibodies; HLA, human leucocyte antigen; anti-LKM1, antibodies to liver/kidney microsome type 1; APS1, autoimmune polyglandular syndrome type 1 ; anti-SLA, antibodies to soluble liver antigen; anti-LP, antibodies to liver pancreas; anti-SLA/LP, antibodies to soluble liver antigen/liver pancreas; tRNP ${ }^{(\mathrm{Ser}) \text { Sec }}$, transfer RNA-protein complex; PBC, primary biliary cirrhosis; PSC, primary sclerosing cholangitis; AMA,

antimitochondrial antibodies; ALP:AST, serum alkaline phosphatase level to serum aspartate aminotransferase level. 
Table 1 Characteristics of the variant syndromes

\begin{tabular}{|c|c|c|c|c|}
\hline Variant syndrome & Clinical features & Laboratory features & Serological findings & Histological features \\
\hline $\mathrm{AIH}+\mathrm{PBC}$ & $\begin{array}{l}\text { Fatigue, jaundice, } \\
\text { immune disease }\end{array}$ & $\begin{array}{l}\text { Cholestatic and hepatitic tests, } \\
\text { increased IgM and IgG levels }\end{array}$ & AMA (M2), ANA, SMA & $\begin{array}{l}\text { Interface hepatitis, cholangitis, } \\
\text { copper deposition }\end{array}$ \\
\hline $\mathrm{AIH}+\mathrm{PSC}$ & $\begin{array}{l}\text { Ulcerative colitis, } \\
\text { pruritus, abnormal } \\
\text { cholangiogram }\end{array}$ & $\begin{array}{l}\text { Cholestatic and hepatitic tests, } \\
\text { ALP:AST }>1.5 \text {, increased IgG } \\
\text { level }\end{array}$ & ANA, SMA, none of above & Cholangitis \\
\hline $\mathrm{AIH}+$ viral $(\mathrm{HCV})$ & Fatigue & Hepatitic tests, viraemia by PCR & $\begin{array}{l}\text { Autoimmune-type: ANA and/or } \\
\text { SMA } \geqslant 1: 320 \text {, increased } \gamma \text {-globulin } \\
\text { level, anti-LKM1 reactive to core } \\
\text { epitope } 257-269 \\
\text { Viral-type: ANA and SMA } \leqslant 1: 80 \text {, } \\
\text { anti-LKM1 reactive to non-core } \\
\text { epitopes }\end{array}$ & $\begin{array}{l}\text { Autoimmune predominant: interface } \\
\text { hepatitis, portal plasma cells, no viral } \\
\text { features } \\
\text { Viral predominant: portal lymphoid } \\
\text { aggregates and steatosis }\end{array}$ \\
\hline AIC & Fatigue, pruritus & $\begin{array}{l}\text { Cholestatic and hepatitic tests, } \\
\text { increased IgG level }\end{array}$ & $\begin{array}{l}\text { AMA negative, ANA and/or SMA } \\
\text { positive }\end{array}$ & $\begin{array}{l}\text { Cholangitis (PBC-like), ductopenia, } \\
\text { little or no portal inflammation } \\
\text { (PSC-like) }\end{array}$ \\
\hline
\end{tabular}

$\overline{\mathrm{AIH}}$, autoimmune hepatitis; PBC, primary biliary cirrhosis; PSC, primary sclerosing cholangitis; HCV, hepatitis C virus; AIC, autoimmune cholangitis; IgM, serum immunoglobulin M; IgG, serum immunoglobulin G; AMA, antimitochondrial antibodies; ANA, antinuclear antibodies; SMA, smooth muscle antibodies; ALP:AST, serum alkaline phosphatase to aspartate aminotransferase ratio; PCR, polymerase chain reaction.

hereditary liver disease. Laboratory features must demonstrate substantial immunoreactivity and liver tissue must disclose at least portal mononuclear cell infiltration and interface hepatitis. The six month requirement to establish chronicity has been waived, and cholestatic clinical, laboratory, and histological changes preclude the diagnosis. A probable diagnosis of AIH requires the same histological findings as for definite disease but there may be less immunoreactivity and some exposure to potentially hepatotoxic drugs or alcohol. ${ }^{50}{ }^{51}$ Furthermore, the probable diagnosis can be supported by demonstration of antibodies to asialoglycoprotein receptor, liver specific cytosolic antigen type 1, SLA/LP, and/or perinuclear antineutrophil cytoplasm..$^{50-53}$

A scoring system can facilitate the diagnosis in patients with mixed manifestations, and it provides a mechanism by which to assess the strength of the diagnosis in different populations..$^{51}$ By weighing each component of the syndrome, discrepant features can be accommodated and biases associated with isolated inconsistencies avoided. The original scoring system has been validated, ${ }^{54}$ and an unintended application has been to use it to assess the resemblance of various chronic liver diseases to classical $\mathrm{AIH}$ in a quantitative and objective fashion. ${ }^{55} 56$

\section{Variant syndromes}

Patients with features of AIH and another liver disease ("overlap syndromes") or with findings that are inconsistent with the definite diagnosis of AIH ("outlier syndromes") constitute the variant syndromes. ${ }^{56-60}$ These variant forms have been reported extensively but the overall experience with these conditions remains relatively small and anecdotal. Standardised diagnostic criteria have not been promulgated; experiences between institutions have not been compared; natural history for each variant form remains uncertain; and treatment algorithms have not been validated. Application of the scoring system proposed by the International Autoimmune Hepatitis Group has been useful in providing a template for diagnosis. ${ }^{55} 5659$ This method however has not been validated for sensitivity, and its major value has been to estimate the frequency of occurrence in a systematic fashion. Eighteen per cent of patients with autoimmune liver disease have features that vary from the classical syndromes of $\mathrm{AIH}$, primary biliary cirrhosis (PBC), and primary sclerosing cholangitis (PSC), ${ }^{56} 59$ and patients with PSC most commonly have concurrent features of $\mathrm{AIH}$ that confound the diagnosis. ${ }^{55659}$ Recognition of these variants is important because they are common; their inclusion in classical diagnostic categories can distort perceptions of disease behaviour and outcome; responsiveness to conventional therapies may vary; and they may provide clues to the pathogenesis of the typical disorders. ${ }^{61}$

AIH AND PBC

$\mathrm{AIH}$ and PBC are generally easy to discriminate on the basis of clinical, laboratory, and histological findings. Patients with AIH however may have antimitochondrial antibodies (AMA), including those against the PBC specific M2 antigens (up to $8 \%$ occurrence). ${ }^{49}{ }^{62}$ Consequently, the scoring system for $\mathrm{AIH}$ was adjusted to allocate greater weight against $\mathrm{PBC}$ by increasing the negative deduction for AMA seropositivity from -1 to $-4 .^{51}$

Histological features of cholangitis, including destructive cholangitis, may also be present in $\mathrm{AIH},{ }^{63-65}$ and copper stains of hepatic tissue may be positive and indicative of chronic cholestasis. ${ }^{62}$ The scoring system for AIH was adjusted further to accommodate these observations by increasing the negative deduction for histological evidence of bile duct injury from -1 to $-3 .^{51}$

The presence of AMA seropositivity and cholestatic clinical, laboratory, and/or histological features in patients with AIH indicates the overlap syndrome of AIH and PBC (table 1). Retrospective analyses indicate that this variant occurs in $5 \%$ of patients with AIH and in $19 \%$ of patients with PBC. ${ }^{56}{ }^{59}$ Disease behaviour and treatment response depend mainly on the component of the AIH-PBC overlap that predominates. Patients with mostly AIH have high serum aspartate aminotransferase levels, serum alkaline phosphatase concentrations less than twofold normal, moderate to severe interface hepatitis on histological examination, and high diagnostic scores for AIH (aggregate scores $\geqslant 10$ ). These individuals commonly respond to corticosteroid therapy (fig 1)..$^{5696264-66}$

In contrast, patients with mainly features of PBC have pronounced cholestatic features manifested by serum alkaline phosphatase levels greater than twofold normal, serum $\gamma$-glutamyl transpeptidase concentrations at least fivefold normal, and florid bile duct lesions on histological examination (fig 1). ${ }^{67}$ These individuals commonly achieve a complete biochemical response on a combination of corticosteroids and ursodeoxycholic acid. Cyclosporine A has also been used successfully in one patient who was recalcitrant to both corticosteroids and ursodeoxycholic acid. ${ }^{68}$

Treatment response may relate to the stage of PBC which is present at accession and the genetic factors that affect outcome in AIH. Early stage PBC may lack the classical histological changes and resemble AIH. ${ }^{69}$ These 


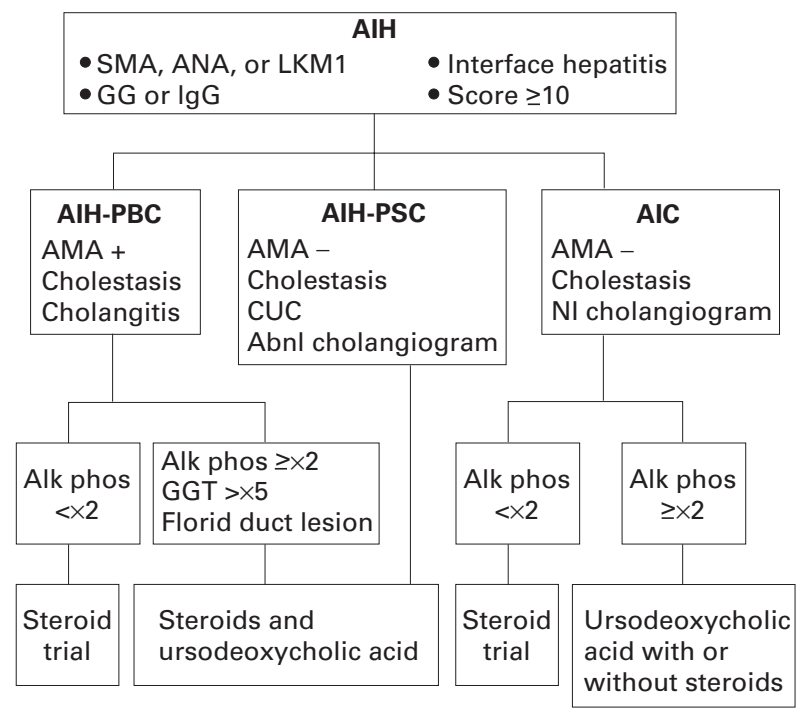

Figure 1 Diagnostic and treatment algorithm for variant syndromes of autoimmune hepatitis (AIH). Seropositivity for smooth muscle antibodies $(S M A)$, antinuclear antibodies (ANA), and/or antibodies to liver/kidney microsome type 1 (anti-LKM1), abnormal serum gamma globulin (GG) or immunoglobulin $G$ (IgG) level, interface hepatitis on histological examination, and/or an aggregate score of at least 10 by the modified system of the International Autoimmune Hepatitis Group support the diagnosis of AIH. Concurrent findings of antimitochondrial antibodies $(A M A+)$, cholestatic clinical and/or laboratory features, and histological evidence of cholangitis indicate an overlap syndrome with primary biliary cirrhosis (AIH-PBC). Cholestatic clinical and/or laboratory features, absence of antimitochondrial antibodies $(A M A-)$, concurrent chronic ulcerative colitis (CUC), and an abnormal (Abnl) cholangiogram indicate an overlap syndrome with primary sclerosing cholangitis (AIH-PSC). Similar clinical, laboratory, and histological findings in the absence of CUC and with a normal (Nl) cholangiogram suggest the outlier syndrome of autoimmune cholangitis (AIC). Treatment decisions are based on the predominant manifestations of the disease, as assessed mainly by serum alkaline phosphatase (Alk phos) or $\gamma$-glutamyl transpeptidase (GGT) levels, serum titres of ANA and/or SMA, and histological features.

patients may yet evolve to classical PBC but at the time of diagnosis they may be responsive to therapy with corticosteroids. ${ }^{65}{ }^{66} 70$ Similarly, the genetic risk factors that affect the susceptibility and outcome of AIH may influence the clinical expression and corticosteroid responsiveness of patients with hybrid features. Individuals with a "hepatitic" form of PBC frequently are positive for HLA B8, DR3, or DR4 ${ }^{66}$ and these genetic markers can be shared in all forms of autoimmune liver disease with a variable impact on disease behaviour. ${ }^{71-73}$

A diagnostic algorithm that has been proposed for the AIH-PBC variant requires the presence of at least two of three accepted criteria for each disease in the same patient (fig 1). ${ }^{67}$ This diagnostic formula is arbitrary, and its sensitivity for the syndrome has not been established. Nevertheless, it does provide a diagnostic template that can be consistently applied. An alternative approach is to designate only those individuals who have scores sufficient for the probable diagnosis of AIH (aggregate scores $\geqslant 10$ ), seropositivity for AMA, and cholangitis on histological examination as AIH-PBC variants (fig 1)..$^{561}$ This strategy is compromised by revisions of the scoring system for AIH that promise to eliminate incompatible diagnoses. ${ }^{51}$ More stringent diagnostic criteria for AIH will enlarge the pool of individuals with non-diagnostic findings and increase the heterogeneity of patients with variant syndromes. ${ }^{57} 58$

AIH AND PSC

Histological changes of lymphocytic, pleomorphic, or fibrous cholangitis, concurrent inflammatory bowel disease, and/or failure to respond to corticosteroids are justifications for cholangiography in patients with AIH. ${ }^{5658561}$
As many as $41 \%$ of these individuals have cholangiographic changes of PSC and are classifiable as AIH-PSC variants (table 1). ${ }^{74}$ Similarly, $54 \%$ of patients with PSC have aggregate scores for $\mathrm{AIH}$ that indicate the probability of coexistent AIH and PSC. ${ }^{55}{ }^{56}$ In $2 \%$ of these patients, the diagnostic criteria for definite $\mathrm{AIH}$ are satisfied. ${ }^{55}$ PSC shares genetic risk factors with AIH (HLA B8, DR3, and Drw52), ${ }^{73-78}$ and this host related predisposition may result in similar clinical expressions or in transitions between the diseases. ${ }^{79-85}$ Conversely, HLA DR4, which predisposes to $\mathrm{AIH}$, protects against PSC, and its presence does not support a strong PSC component of the variant syndrome. ${ }^{64}{ }^{73}$

Diagnostic difficulties occur mainly in children and in adults with normal cholangiograms. "Autoimmune sclerosing cholangitis" is a disorder described in children who have the clinical phenotype of AIH but abnormal cholangiograms. ${ }^{27}{ }^{86-89}$ Because these children have clinical features of $\mathrm{AIH}$ and cholangiographic changes of PSC, they satisfy criteria for an overlap syndrome. Inflammatory bowel disease however is typically absent; cholestasis is neither a biochemical nor a histological feature; and response to corticosteroid therapy is similar to that in classical type $1 \mathrm{AIH} .^{27} 8688{ }^{89}$ Consequently, they are distinct from the AIH-PSC syndrome reported in adults and are best categorised separately until their true nature is fully defined.

Adults with $\mathrm{AIH}$, cholestatic features, seronegativity for AMA, and normal cholangiograms are another diagnostic problem as they may have small duct PSC $^{74}$ or autoimmune cholangitis (AIC) ${ }^{64}$ High serum alkaline phosphatase activity or a ratio of serum alkaline phosphatase level to aspartate aminotransferase level (ALP: AST) that exceeds 1.5 suggests the existence of an AIH-PSC overlap, especially if biliary changes are evident on liver biopsy examination and inflammatory bowel disease is present. ${ }^{83}$ The scoring system of the International Autoimmune Hepatitis Group has been modified to separate patients with PSC from those of $\mathrm{AIH}$, mainly by assigning no points to ALP:AST ratios of 1.5-3.0 and deducting two points from the aggregate score if the ratio exceeds 3.0. ${ }^{51}$ Currently, the only distinguishing clinical feature between small duct PSC and AIC is the presence or absence of inflammatory bowel disease.

There is no established treatment for the AIH-PSC variant (fig 1). Corticosteroid therapy has been associated with normalisation of serum aminotransferase levels and improvement in the histological features of inflammation in some patients. ${ }^{81}{ }^{83}$ In others, corticosteroid therapy has been ineffective. ${ }^{56}{ }^{74}$ Treatment is empiric, and it should be tailored to the predominant manifestations of the hybrid syndrome. The potential for a corticosteroid response is reserved for those individuals with serum alkaline phosphatase levels below twofold normal. ${ }^{56}{ }^{59}$ Ursodeoxycholic acid can be considered for those individuals with dominant cholestatic features but it has generally not been useful in PSC at conventional doses. ${ }^{91}$ The combination of corticosteroids and ursodeoxycholic acid manages all aspects of the disease and intuitively is the most appealing treatment (fig 1). Its value however is uncertain, and the expectation that two different ineffective therapies will be more successful when administered together is low.

\section{AIH AND VIRAL HEPATITIS}

$\mathrm{AIH}$ is by definition a non-viral disease $\mathrm{e}^{51}$ but there is an association between viral infection and the autoimmune response. ${ }^{92}$ Autoantibodies commonly occur in chronic hepatitis B and C infection. ${ }^{93-101}$ Indeed, ANA and/or SMA occur in $20-40 \%$ of patients with chronic hepatitis B or $\mathrm{C}^{9799}$; anti-LKM1 are detectable in up to $6 \%$ of adult 
patients ${ }^{101-108}$ and $10 \%$ of children with chronic hepatitis $\mathrm{C}^{22}{ }^{98}$; antibodies to LKM3 are found in $13 \%$ of patients with chronic hepatitis $\mathrm{D}^{107}{ }^{109}$; immune diseases that are viral-antigen driven (cryoglobulinaemia) or autoantigen driven (autoimmune thyroiditis, Sjogren's syndrome) frequently coexist ${ }^{110-116}$; and corticosteroids may be effective in some patients. ${ }^{117-123}$ In most individuals, the viral components predominate, and these patients are best designated as "chronic viral hepatitis with autoimmune features" and treated accordingly. ${ }^{124}$ Rarely, the autoimmune features predominate, and the concurrent true viral infection is coincidental or aetiological but non-essential for perpetuation of the disorder. ${ }^{118} 119125$ These latter patients constitute the overlap syndrome of AIH and true viral infection (table 1)..$^{58}{ }^{126}$ Their diagnosis requires the clinical, laboratory, and histological features of classical AIH.

Candidates for designation as an AIH-viral hepatitis overlap are patients with high titre SMA and/or ANA (titres, $\geqslant 1: 320$ ) and hypergammaglobulinaemia (table 1). ${ }^{125} 126$ These patients commonly are HLA DR3 positive, and examination of the liver tissue usually discloses moderate to severe interface hepatitis with or without panacinar hepatitis. ${ }^{125127} 128$ Titres of anti-LKM1 do not distinguish patients with and without chronic hepatitis $\mathrm{C},{ }^{22}{ }^{123}$ and anti-LKM1 in any titre may denote an AIH-viral hepatitis overlap syndrome. Histological features of viral infection, such as steatosis and portal lymphoid aggregates, are typically absent in patients with the AIH-viral hepatitis variant (fig 1). ${ }^{125} 129130$

Multiple studies have now indicated that the rare patients with AIH-viral hepatitis overlap can respond to corticosteroid treatment (fig 1). ${ }^{118}{ }^{120-123}$ Anecdotal reports of exacerbations of inflammatory activity or worsening of autoimmune manifestations after interferon treatment have justified this alternative management strategy in highly selected patients. ${ }^{123}{ }^{131-136}$ Instances of deterioration during interferon treatment however have been rare, and the routine precautionary use of corticosteroids in individuals without definite $\mathrm{AIH}$ is unjustified. ${ }^{96}{ }^{136-141}$ These patients however must be monitored closely during interferon therapy, especially those with anti-LKM1, for exacerbation of their disease. ${ }^{101}$ Fortunately, the AIH-viral hepatitis variant is rare and it may be a serendipitous clustering of separate diseases rather than a single entity.

AUTOIMMUNE CHOLANGITIS

Autoimmune cholangitis is an "outlier" rather than an "overlap" syndrome. ${ }^{56-59}$ Clinical and/or laboratory features of cholestasis are present as are high titres of ANA and/or SMA. Antimitochondrial antibodies are undetectable, and bile duct injury is evident in liver tissue. The diagnosis implies the absence of inflammatory bowel disease and/or a normal cholangiogram (table 1$).^{56-59}$

Retrospective analyses that have used patients with PBC as discovery fields for the diagnosis have emphasised its resemblance to PBC. In these studies, patients with AIC have been indistinguishable from those with PBC by histological examination ${ }^{142}$; display of pyruvate dehydrogenase complexes on biliary epithelia ${ }^{143}$; presence of PBC specific antibodies to 2-oxo-acid dehydrogenase complex in blood $^{144-146}$; clinical and laboratory features ${ }^{147}$; and responsiveness to ursodeoxycholic acid. ${ }^{148}$ Conversely, retrospective analyses using patients with $\mathrm{AIH}$ as discovery fields for the diagnosis have emphasised its resemblance to AIH. In these studies, patients with autoimmune cholangitis have had ANA and/or SMA, ${ }^{149-151}$ interface hepatitis and portal plasma cell infiltration, ${ }^{149} 151$ high mean diagnostic scores for $\mathrm{AIH},{ }^{565864152}$ and occasional improvement after corticosteroid therapy. ${ }^{151}$
Autoimmune cholangitis is probably a heterogeneous syndrome that includes patients with AMA negative PBC, small duct PSC, AIH with bile duct damage, concurrent AIH and small duct PSC, and various transition states. ${ }^{64}$ Prospective studies have emphasised the inability to classify these individuals into a single diagnostic category. Histological findings may be indistinguishable from PBC or PSC, and individual patients cannot be discriminated by clinical, laboratory, genetic, or histological parameters. ${ }^{64}$ Similarly, responsiveness to corticosteroids or ursodeoxycholic acid is variable and generally poor. Indeed, most studies emphasise an inability to induce histological improvement with either drug. ${ }^{64} 150151$ Treatment is empiric and consists of corticosteroids, ursodeoxycholic acid, or a combination of both (fig 1). Therapy should be reserved mainly for those individuals who are symptomatic with jaundice, pruritus, and/or malaise.

\section{Summary}

The characteristic features of the variant syndromes of AIH are summarised in table 1. The presence of AMA, histological features of cholangitis, abnormal cholangiogram, disproportionate elevation of the serum alkaline phosphatase level, laboratory features of cholestasis, and/or concurrent true viral infection in individuals who otherwise have classical features of AIH constitute the variant forms.

The variant syndromes are in part the result of improved diagnostic criteria that exclude patients with cholestatic and viral features from the diagnosis of AIH. Their frequency emphasises the variability of the classical syndromes of autoimmune liver disease, and it suggests that the classical disorders share genetic predispositions and/or pathogenic mechanisms that can result in hybrid syndromes, concurrent diseases, or transition states. The variant syndromes should be classified separately until their nature is fully defined. In this fashion, the natural history of the established disorders can be preserved, and the pathogenic pathways of the newly recognised entities examined. Treatments are empiric until diagnostic criteria can be codified and multicentre clinical trials instituted. The variant syndromes may reflect the "larval stage" of a classical syndrome, a collage of different autoimmune manifestations in a susceptible host, a unique expression of coincidental factors that are unrelated, or an independent complex disorder with a heterogeneous phenotype. Each syndrome should stand alone until its true identity is revealed.

Z BEN-ARI Liver Transplant Unit, Rabin Medical Center, Beilinson Campus, Petah Tiqva, Israel

A J CZAJA,

Division of Gastroenterology and Hepatology, Mayo Clinic, Rochester, Minnesota, USA

Correspondence to: Dr A J Czaja, Mayo Clinic, 200 First Street S W, Rochester, Minnesota 55905, USA. czaja.albert@mayo.edu

1 Czaja AJ. Natural history, clinical features, and treatment of autoimmune hepatitis. Semin Liver Dis 1984;4:1-12

2 Czaja AJ. Autoimmune hepatitis: evolving concepts and treatment strategies. Dig Dis Sci 1995;40:435-56.

3 Czaja AJ. Drug therapy in the management of type 1 autoimmune hepatitis. Drugs 1999;57:49-68.

4 Obermayer-Straub P, Strassburg CP, Manns MP. Autoimmune hepatitis. $\mathcal{F}$ Hepatol 2000;32(suppl 1):181-97.

5 Boberg KM, Aadland E, Jahnsen J, et al. Incidence and prevalence of primary biliary cirrhosis, primary sclerosing cholangitis, and autoimmune hepatitis in a Norwegian population. Scand $\mathcal{F}$ Gastroenterol 1998;33:99-103.

6 Jacobson DL, Gange SJ, Rose NR, et al. Epidemiology and estimated population burden of selected autoimmune diseases in the United States. Clin Immunol Immunopathol 1997;84:223-43.

7 Milkiewicz P, Hubscher SG, Skiba G, et al. Recurrence of autoimmune hepatitis after liver transplantation. Transplantation 1999;68:253-6.

8 Wiesner RH, Demetris AJ, Belle SH, et al. Acute allograft rejection: incidence, risk factors, and impact on outcome. Hepatology 1998;28:63845. 
9 Czaja AJ, Manns MP. The validity and importance of subtypes of autoimmune hepatitis: a point of view. Am f Gastroenterol 1995;90:120611

10 Donaldson PT, Doherty DG, Hayllar KM, et al. Susceptibility to autoimmune chronic active hepatitis: human leukocyte antigens DR4 an A1-B8-DR3 are independent risk factors. Hepatology 1991;13:701-6.

11 Strettell MDJ, Donaldson PT, Thomson LJ, et al. Allelic basis for HLA-encoded susceptibility to type 1 autoimmune hepatitis. Gastroenterology 1997;112:2028-35

12 Czaja AJ, Strettell MDJ, Thomson LJ, et al. Associations between alleles of the major histocompatibility complex and type 1 autoimmune hepatitis. Hepatology 1997;25:317-23.

13 Czaja AJ, Rakela J, Hay JE, et al. Clinical and prognostic implications of human leukocyte antigen B8 in corticosteroid-treated severe autoimmune chronic active hepatitis. Gastroenterology 1990;98:1587-93.

14 Sanchez-Urdazpal L, Czaja AJ, van Hoek B, et al. Prognostic features and role of liver transplantation in severe corticosteroid-treated autoimmune role of liver transplantation in severe corticosteroid-
chronic active hepatitis. Hepatology 1992;15:215-21.

15 Czaja AJ, Carpenter HA, Santrach PJ, et al. Significance of HLA DR4 in type 1 autoimmune hepatitis. Gastroenterology 1993;105:1502-7.

16 Homberg J-C, Abuaf N, Bernard O, et al. Chronic active hepatitis associated with antiliver/kidney microsome antibody type 1: a second type of "autoimmune" hepatitis. Hepatology 1987;7:1333-9.

17 Manns MP, Johnson EF, Griffin KJ, et al. Major antigen of liver kidney microsomal autoantibodies in idiopathic autoimmune hepatitis is cytochrome P450db1. F Clin Invest 1989;83:1066-72.

18 Manns MP, Griffin KJ, Sullivan KF, et al. LKM-1 autoantibodies recognize a short linear sequence in P450IID6, a cytochrome P-450 monooxygenase. $\mathcal{f}$ Clin Invest 1991;88:1370-8.

19 Yamamoto AM, Cresteil D, Boniface $\mathrm{O}$, et al. Identification and analysis of cytochrome P4502D6 antigenic sites recognized by anti-liver-kidney microsome type-1 antibodies (LKM1). Eur F Immunol 1993;23:1105-11.

20 Kerkar N, Mahmoud A, Muratori L, et al. New viral triggers of autoreactivity to cytochrome P4502D6, the target of liver kidney microsomal autoanity to cytochrome P4502D6,
tibody. F Hepatol 1999;30:58.

21 Lunel F, Abuaf N, Frangeul L, et al. Liver/kidney microsome antibody type 1 and hepatitis C virus infection. Hepatology 1992;16:630-6.

22 Ma Y, Peakman M, Lobo-Yeo A, et al. Differences in immune recognition of cytochrome P4502D6 by liver kidney microsomal (LKM) antibody in autoimmune hepatitis and chronic hepatitis C virus infection. Clin Exp Immunol 1994;97:94-9.

23 Czaja AJ, Kruger M, Santrach PJ, et al. Genetic distinctions between types 1 and 2 autoimmune hepatitis. Am f Gastroenterol 1997;92:2197-200.

24 Bittencourt PL, Goldberg AC, Cancado ELR, et al. Genetic heterogeneity in susceptibility to autoimmune hepatitis types 1 and 2 . Am $\mathcal{F}$ Gastroenterol 1999;94:1906-13.

25 Manns MP, Kruger M. Immunogenetics of chronic liver diseases. Gastroenterology 1994;106:1676-97.

26 Maggiore G, Bernard O, Homberg JC, et al. Liver disease associated with anti-liver-kidney microsome antibody in children. F Pediatr 1986;108:399404.

27 Gregorio GV, Portmann B, Reid F, et al. Autoimmune hepatitis in childhood. A 20 year survey. Hepatology 1997;25:541-7.

28 Porta G, Da Costa Gayotto LC, Alvarez F. Anti-liver-kidney microsome antibody-positive autoimmune hepatitis presenting as fulminant liver failure. F Pediatr Gastroenterol Nutr 1990;11:138-40.

29 Nikias GA, Batts KP, Czaja AJ. The nature and prognostic implications of autoimmune hepatitis with an acute presentation. F Hepatol 1994;21:86671. 30 Burgart LJ, Batts KP, Ludwig J, et al. Recent onset autoimmune hepatitis:
biopsy findings and clinical correlations. Am $\mathcal{F}$ Surg Pathol 1995;19:699708.

31 Ahonen P, Myllarmiemi S, Sipila I, et al. Clinical variation of autoimmune polyendocrinopathy-candidiasis-ectodermal dystrophy (APECED) in a series of 68 patients. N Engl F Med 1990;322:1829-36.

32 Michele TM, Fleckenstein J, Sgrignoli AR, et al. Chronic active hepatitis in the type 1 polyglandular autoimmune syndrome. Postgrad Med f 1994;70:
$128-31$.

33 Hannigan NR, Jabs K, Perez-Atayde AR, et al. Autoimmune interstitial nephritis and hepatitis in polyglandular autoimmune syndrome. Pediatr nephritis and hepatitis in
Nephrol 1996;10:511-14.

34 Aaltonen J, Borses P, Sandkuijl L, et al. An autosomal locus causing autoimmune disease: autoimmune polyglandular disease type 1 assigned to chromosome 21. Nat Genet 1994;8:83-7.

35 Consortium TF-GA. An autoimmune disease, APECED, caused by mutations in a novel gene featuring two PHD-type zinc finger domains. Nat Genet 1997;17:399-403.

36 Clemente MG, Obermayer-Straub P, Meloni A, et al. Cytochrome P450 $1 \mathrm{~A} 2$ is a hepatic autoantigen in autoimmune polyglandular syndrome type 1. F Clin Endocrinol Metab 1997;82:1353-61.

37 Clemente MG, Meloni A, Obermayer-Straub P, et al. Two cytochromes P450 are major hepatocellular autoantigens in autoimmune polyglandular syndrome type 1. Gastroenterology 1998;114:324-8.

38 Choudhuri K, Gregorio GV, Mieli-Vergani G, et al. Immunological cross-reactivity to multiple autoantigens in patients with liver kidney cross-reactivity to multiple autoantigens in patients with liver kidney
microsomal type 1 autoimmune hepatitis. Hepatology 1998;28:1177-81.

39 Manns M, Gerken G, Kyriatsoulis A, et al. Characterization of a new subgroup of autoimmune chronic active hepatitis by autoantibodies against a soluble liver antigen. Lancet 1987;1:292-4.

40 Stechemesser E, Klein R, Berg PA. Characterization and clinical relevance of liver-pancreas antibodies in autoimmune hepatitis. Hepatology 1993;18: $1-9$.

41 Klein R, Berg PA. Glutathione S-transferase as a major autoantigen in antiSLA-positive autoimmune hepatitis (letter to editor). Gastroenterology 1999;116:1015-16.

42 Kanzler S, Weidemann C, Gerken G, et al. Clinical significance of autoantibodies to soluble liver antigen in autoimmune hepatitis. F Hepatol 1999;31: $635-40$.

43 Wachter B, Kyriatsoulis A, Lohse AW, et al. Characterization of liver cytokeratin as a major target antigen of anti-SLA antibodies. F Hepatol 1990;11: $232-9$.

44 Wesierska-Gadek J, Grimm R, Hitchman E, et al. Members of the glutathione S-transferase gene family are antigens in autoimmune hepatitis. Gastroenterology 1998;114:329-35.
45 Wies I, Brunner S, Henninger J, et al. Identification of target antigen for SLA/LP autoantibodies in autoimmune hepatitis. Lancet 2000;355:151015 .

46 Costa M, Rodriques-Sanchez JL, Czaja AJ, et al. Isolation and characterization of cDNA encoding the antigenic protein of the human $\mathrm{tRNP}^{(\mathrm{Ser}) \mathrm{Sec}}$ complex recognized by autoantibodies from patients
autoimmune hepatitis. Clin Exp Immunol 2000;121:364-74.

47 Gelpi C, Sontheimer EJ, Rodriguez-Sanchez JL. Autoantibodies against a serine tRNA-protein complex implicated in cotranslational selenocysteine insertion. Proc Natl Acad Sci USA 1992;89:9739-43.

$48 \mathrm{Ma} Y$, Okamoto M, Thomas MG, et al. Autoantibodies to soluble liver antigen/UGA suppressor tRNA-associated antigenic protein are specific to autoimmune liver disease. Hepatology 2000;32:310A.

49 Czaja AJ, Carpenter HA, Manns MP. Antibodies to soluble liver antigen, P450IID6, and mitochondrial complexes in chronic hepatitis. Gastroenterology 1993;105:1522-8.

50 Johnson PJ, McFarlane IG, Alvarez F, et al. Meeting Report. International Autoimmune Hepatitis Group. Hepatology 1993;18:998-1005.

51 Alvarez F, Berg PA, Bianchi FB, et al. International Autoimmune Hepatitis Group report: review of criteria for diagnosis of autoimmune hepatitis. $\mathcal{F}$ Hepatol 1999;31:929-38.

52 Czaja AJ. Autoantibodies. Baillieres Clin Gastroenterol 1995;9:723-44.

53 Czaja AJ, Homburger HA. Autoantibodies in liver disease. Gastroenterology 2001;120:239-49.

54 Czaja AJ, Carpenter HA. Validation of a scoring system for the diagnosis of autoimmune hepatitis. Dig Dis Sci 1996;41:305-14.

55 Boberg KM, Fausa O, Haaland T, et al. Features of autoimmune hepatitis in primary sclerosing cholangitis: an evaluation of 114 primary sclerosing cholangitis patients according to a scoring system for the diagnosis of autoimmune hepatitis. Hepatology 1996;23:1369-76.

56 Czaja AJ. Frequency and nature of the variant syndromes of autoimmune liver disease. Hepatology 1998;28:360-5.

57 Czaja AJ. Chronic active hepatitis: the challenge for a new nomenclature. Ann Intern Med 1993;119:510-17.

58 Czaja AJ. The variant forms of autoimmune hepatitis. Ann Intern Med 1996; 125:588-98.

59 Czaja AJ. Variant forms of autoimmune hepatitis. Curr Gastroenterol Rep

60 Woodward J, Neuberger J. Autoimmune overlap syndromes. Hepatology 2001;33:994-1002

61 Czaja AJ, Manns MP, McFarlane IG, et al. Autoimmune hepatitis: the investigational and clinical challenges. Hepatology 2000;31:1194-200.

62 Kenny RP, Czaja AJ, Ludwig J, et al. Frequency and significance of antimitochondrial antibodies in severe chronic active hepatitis. Dig Dis Sci 1986; 31:705-11.

63 Ludwig J, Czaja AJ, Dickson ER, et al. Manifestations of nonsuppurative cholangitis in chronic hepatobiliary disease: morphologic spectrum, clinical correlations and terminology. Liver 1984;4:105-16.

64 Czaja AJ, Carpenter HA, Santrach PJ, et al. Autoimmune cholangitis within the spectrum of autoimmune liver disease. Hepatology 2000;31:1231-8.

65 Geubel AP, Baggenstoss AH, Summerskill WHJ. Responses to treatment can differentiate chronic active liver disease with cholangitic features from the primary biliary cirrhosis syndrome. Gastroenterology 1976;71:444-9.

66 Lohse AW, Meyer zum Buschenfelde KH, Kanzler FB, et al. Characterization of the overlap syndrome of primary biliary cirrhosis (PBC) and autoimmune hepatitis: evidence for it being a hepatitic form of PBC in genetically susceptible individuals. Hepatology 1999;29:1078-84.

67 Chazouilleres O, Wendum D, Serfaty L, et al. Primary biliary cirrhosisautoimmune hepatitis overlap syndrome: clinical features and response to therapy. Hepatology 1998;28:296-301.

68 Duclos-Vallee J-C, Hadengue A, Ganne-Carrie N, et al. Primary biliary cirrhosis-autoimmune hepatitis overlap syndrome: corticoresistance and effective treatment with cyclosporine A. Dig Dis Sci 1995;40:1069-73.

69 Metcalf J, Mitchison HC, Palmer JM. Natural history of early primary biliary cirrhosis. Lancet 1996;348:1399-402.

70 Leuschner M, Guldutuna S, You T, et al. Ursodeoxycholic acid and prednisolone versus ursodeoxycholic acid and placebo in the treatment of early stages of primary biliary cirrhosis. $\mathcal{F}$ Hepatol 1996;25:49-57.

71 Czaja AJ, Carpenter HA, Santrach PJ, et al. Genetic predispositions for immunological features in chronic liver diseases other than autoimmune hepatitis. F Hepatol 1996;24:52-9.

72 Czaja AJ, Dos Santos RM, Porto A, et al. Immune phenotype of chronic liver

disease. Dig Dis Sci 1998;43:2149-55.
73 Czaja AJ, Santrach PJ, Moore SB. Shared genetic risk factors in autoimmune liver disease. Dig Dis Sci $2001 ; 46: 140-7$.

74 Perdigoto R, Carpenter HA, Czaja AJ. Frequency and significance of chronic ulcerative colitis in severe corticosteroid-treated autoimmune hepatitis. F Hepatol 1992;14:325-31.

75 Chapman RW, Varghese Z, Gaul R, et al. Association of primary sclerosing cholangitis with HLA-B8. Gut 1983;24:38-41.

76 Prochazka EJ, Terasaki PI, Park MS, et al. Association of primary sclerosing cholangitis with HLA-DRw52a. N Engl f Med 1990;322:1842-4.

77 Donaldson PT, Farrant JM, Wilkinson ML, et al. Dual association of HLA DR2 and DR3 with primary sclerosing cholangitis. Hepatology 1991;13: 129-33.

78 Farrant JM, Doherty DG, Donaldson PT, et al. Amino acid substitutions at position 38 of the DR $\beta$ polypeptide confer susceptibility to and protection from primary sclerosing cholangitis. Hepatology 1992;16:390-5.

79 Rabinovitz M, Demetris AJ, Bou-Abboud CF, et al. Simultaneous occurrence of primary sclerosing cholangitis and autoimmune chronic active hepatitis in a patient with ulcerative colitis. Dig Dis Sci 1992;37:1606-11

80 Wurbs D, Klein R, Terracciano L-M, et al. A 28-year-old woman with a combined hepatitic/cholestatic syndrome. Hepatology 1995;22:1598-605.

81 Gohlke F, Lohse AW, Dienes HP, et al. Evidence for an overlap syndrome of autoimmune hepatitis and primary sclerosing cholangitis. I Hepatol 1996;24:699-705.

82 Luketic VAC, Gomez DA, Sanyal AJ, et al. An atypical presentation for primary sclerosing cholangitis. Dig Dis Sci 1997;42:2009-16.

83 McNair AN, Moloney M, Portmann BC, et al. Autoimmune hepatitis overlapping primary sclerosing cholangitis in five cases. Am $\mathcal{f}$ Gastroenterol 1998;93:777-84. 
84 Koskinas J, Raptis I, Manika Z, et al. Overlapping syndrome of autoimmune hepatitis and primary sclerosing cholangitis associated with pyoderma gangrenosum and ulcerative colitis. Eur f Gastroenterol Hepatol 1999;11:1421-

mune hepatitis and primary sclerosing cholangitis in two cases. Eur $\mathcal{f}$ Gastroenterol Hepatol 2000;12:559-64.

86 Mieli-Vergani G, Vergani D. Immunological liver diseases in children. Semin Liver Dis 1998;18:271-9.

87 Roberts EA. Primary sclerosing cholangitis in children. $f$ Gastroenterol Hepatol 1999;14:588-93.

88 Mieli-Vergani G. Autoimmune sclerosing cholangitis: a distinct clinical entity? f Hepatol 2000;32(suppl 2):7-8.

89 Gregorio G, Portmann B, Karani J, et al. Autoimmune hepatitis/sclerosing cholangitis overlap syndrome in childhood: a 16-year prospective study. Hepatology 2001;33:544-53.

90 Wee A, Ludwig J. Pericholangitis in chronic ulcerative colitis: primary sclerosing cholangitis of the small bile ducts? Ann Intern Med 1985;102:581-7.

91 Lindor KD. Ursodiol for primary sclerosing cholangitis. N Engl f Med 1997; 336:691-5.

92 Zinkernagel RM. Immunology taught by viruses. Science 1996;271:173-8.

93 Cassani F, Muratori L, Manotti P, et al. Serum autoantibodies and the diagnosis of type-1 autoimmune hepatitis in Italy: a reappraisal at the light of hepatitis C virus infection. Gut 1992;33:1260-3.

94 Abuaf N, Lunel F, Giral P, et al. Non-organ specific autoantibodies associated with chronic C virus hepatitis. F Hepatol 1993;18:359-64.

95 Czaja AJ, Carpenter HA, Santrach PJ, et al. Evidence against hepatitis viruses as important causes of severe autoimmune hepatitis in the United States. F Hepatol 1993;18:342-52.

96 Clifford BD, Donahue D, Smith L, et al. High prevalence of serological markers of autoimmunity in patients with chronic hepatitis C. Hepatology 1995;21:613-19.

97 Czaja AJ, Carpenter HA, Santrach PJ, et al. Immunologic features and HLA associations in chronic viral hepatitis Gastroenterology 1995;108:157-64.

98 Bortolotti F, Vajro P, Balli F, et al. Non-organ specific autoantibodies in children with chronic hepatitis C. $\mathcal{F}$ Hepatol 1996;25:614-20.

99 Cassani F, Cataleta M, Valentini P, et al. Serum autoantibodies in chronic hepatitis C: comparison with autoimmune hepatitis and impact on the disease profile. Hepatology 1997;26:561-6.

100 Gregorio GV, Pensati P, Iorio R, et al. Autoantibody prevalence in children with liver disease due to chronic hepatitis C (HCV) infection. Clin Exp Immunol 1998:112:471-6.

101 Vergani D. NOSA in HCV infection: markers or makers of disease? Gut 1999;45:328-9.

102 Todros L, Touscoz G, D'Urso N, et al. Hepatitis C virus-related chronic liver disease with autoantibodies to liver-kidney microsomes (LKM). Clinical characterization from idiopathic LKM-positive disorders. $\mathcal{F}$ Hepatol 1991;13:128-31.

103 Lunel F, Abuaf N, Frangeul L, et al. Liver/kidney microsome antibody type 1 and hepatitis C virus infection. Hepatology 1992;16:630-6.

104 Yamamoto AM, Cresteil D, Homberg JC, et al. Characterization of the anti-liver-kidney microsome antibody (anti-LKM1) from hepatitis C viruspositive and -negative sera. Gastroenterology 1993;104:1762-7.

105 Gerotto M, Pontisso P, Giostra F, et al. Analysis of the hepatitis C virus genome in patients with anti-LKM-1 autoantibodies. F Hepatol 1994;21: 273-6.

106 Mackie FD, Peakman M, Yun M, et al. Primary and secondary liver/kidney microsomal autoantibody response following infection with hepatitis $\mathrm{C}$ virus. Gastroenterology 1994;106:1672-5.

107 Durazzo M, Philipp T, van Pelt FNAM, et al. Heterogeneity of microsomal autoantibodies (LKM) in chronic hepatitis C and D virus infection. Gastroenterology 1995;108:455-62.

108 Giostra F, Manzin A, Lenzi M, et al. Low hepatitis C viremia in patients with anti-liver/kidney microsomal antibody type 1 positive chronic hepatitis. F Hepatol 1996;25:433-8

109 Manns MP, Obermayer-Straub P. Cytochromes P450 and uridine triphosphate-glucuronosyltransferases: model autoantigens to study druginduced, virus-induced, and autoimmune liver disease. Hepatology 1997;26: $1054-66$.

110 Lunel F, Musset L, Cacoub P, et al. Cryoglobulinemia in chronic liver diseases: role of hepatitis C virus and liver damage. Gastroenterology 1994; 106:1291-300.

111 Pawlotsky J-M, Yahia MB, Andre C, et al. Immunological disorders in C virus chronic active hepatitis: a prospective case-control study. Hepatology 1994;19:841-8.

112 Haddad J, Deny P, Munz-Gotheil C, et al. Lymphocytic sialadenitis of Sjogren's syndrome associated with chronic hepatitis $\mathrm{C}$ virus liver disease. Lancet 1992;339:321-3.

113 Marcellin P, Pouteau M, Benhamou J-P. Hepatitis C virus infection, alpha interferon therapy and thyroid dysfunction. $\mathcal{F}$ Hepatol 1995;22:364-9.

114 Ganne-Carrie N, Medini A, Coderc E, et al. Latent autoimmune thyroiditis in untreated patients with HCV chronic hepatitis: a case-control study. $\mathcal{F}$ Autoimmun 2000;14:189-93.

115 Czaja AJ. Extrahepatic immunologic features of chronic viral hepatitis. Dig Dis 1997;15:125-44

116 Zein NN, Persing DH, Czaja AJ. Viral genotypes as determinants of autoimmune expression in chronic hepatitis C. Mayo Clin Proc 1999;74: 454-60.

117 Fong T-L, Valinluck B, Govindarajan S, et al. Short-term prednisone therapy affects aminotransferase activity and hepatitis C virus RNA levels in chronic hepatitis C. Gastroenterology 1994;107:196-9.

118 Czaja AJ, Magrin S, Fabiano C, et al. Hepatitis C virus infection as a determinant of behavior in type 1 autoimmune hepatitis. Dig Dis Sci 1995;40:33-40.

119 Garcia-Bury L, Garcia-Monzon C, Rodriguez S, et al. Latent autoimmune hepatitis triggered during interferon therapy in patients with chronic hepatitis C. Gastroenterology 1995;108:1770-7.
120 Bellary S, Schiano T, Hartman G, et al. Chronic hepatitis with combined features of autoimmune chronic hepatitis and chronic hepatitis C: favorable response to prednisone and azathioprine. Ann Intern Med 1995;123:32-4. 121 Tran A, Benzaken S, Yang G, et al. Chronic hepatitis C and autoimmunity: good response to immunosuppressive therapy. Dig Dis Sci 1997;42:778-80.

122 Yoshikawa $M$, Toyohara $M$, Yamane $Y$, et al. Disappearance of serum HCV-RNA after short-term prednisolone therapy in a patient with chronic hepatitis $\mathrm{C}$ associated with autoimmune hepatitis-like serological manifestations. F Gastroenterol 1999;34:269-74.

123 Vento S, Cainelli F, Concia E, et al. Steroid and interferon therapy in liver/ kidney microsomal antibody-positive patients with chronic hepatitis C. F Hepatol 1997;26:955-6.

124 Desmet VJ, Gerber M, Hoofnagle JH, et al. Classification of chronic hepatitis: diagnosis, grading and staging. Hepatology 1994;19:1513-20.

125 Czaja AJ, Carpenter HA. Histological findings in chronic hepatitis $\mathrm{C}$ with autoimmune features. Hepatology 1997;26:459-66.

126 Czaja AJ. Overlap of chronic viral hepatitis and autoimmune hepatitis. In: Willson RA ed. Viral hepatitis: diagnosis, treatment, prevention. New York: Marcel Dekker Inc, 1997:371-99.

127 Czaja AJ, Carpenter HA, Santrach PJ, et al. Significance of human leukocyte antigens DR3 and DR4 in chronic viral hepatitis. Dig Dis Sci 1995;40: 2098-106.

128 Muratori L, Zauli D, Giostra F. LMK1 appearance in a HLA-DR3 ${ }^{+}$patient with chronic hepatitis C during interferon treatment. F Hepatol 1993;18: $259-60$

129 Bach N, Thung SN, Schaffner F. The histological features of chronic hepatitis $\mathrm{C}$ and autoimmune chronic hepatitis: a comparative analysis. Hepatology 1992;15:572-7.

130 Czaja AJ, Carpenter HA. Sensitivity, specificity and predictability of biopsy interpretations in chronic hepatitis. Gastroenterology 1993;105:1824-32.

131 Vento S, DiPerri G, Garofano T, et al. Hazards of interferon therapy for HBV-seronegative chronic hepatitis. Lancet 1989;2:926.

132 Shindo M, Di Bisceglie AM, Hoofnagle JH. Acute exacerbation of liver disease during interferon alfa therapy for chronic hepatitis C. Gastroenterology 1992;102:1406-8.

133 Papo T, Marcellin P, Bernuau J, et al. Autoimmune chronic hepatitis exacerbated by alpha-interferon. Ann Intern Med 1992;116:51-3.

134 Mitoro A, Yoshikawa M, Yamamoto K, et al. Exacerbation of ulcerative colitis during alpha-interferon therapy for chronic hepatitis C. Intern Med 1993;32:327-31.

135 Weber $\mathrm{P}$, Wiedmann $\mathrm{K}-\mathrm{H}$, Klein $\mathrm{R}$, et al. Induction of autoimmune phenomena in patients with chronic hepatitis B treated with gammainterferon. F Hepatol 1994;20:321-8.

136 Muratori L, Lenzi M, Cataleta $M$, et al. Interferon therapy in liver/kidney microsomal antibody type 1-positive patients with chronic hepatitis C. $\mathcal{F}$ Hepatol 1994;21:199-203.

137 Saracco G, Touscoz A, Durazzo M, et al. Antibodies and response to alpha-interferon in patients with chronic viral hepatitis. F Hepatol 1990;11: 339-43

138 Wada M, Kang KB, Kinugasa A, et al. Does the presence of serum autoantibodies influence the responsiveness to interferon-alpha 2a treatment in chronic hepatitis C? Intern Med 1997;36:248-54.

139 Todros L, Saracco G, Durazzo M, et al. Efficacy and safety of interferon alfa therapy in chronic hepatitis $\mathrm{C}$ with autoantibodies to liver-kidney microsomes. Hepatology 1995;22:1374-8.

140 Calleja JL, Albillos A, Cacho G, et al. Interferon and prednisone therapy in chronic hepatitis C with non-organ-specific antibodies. F Hepatol 1996;24: 308-12.

141 Duclos-Vallee J-C, Nishioka M, Hosomi N, et al. Interferon therapy in LKM1 positive patients with chronic hepatitis C: follow-up by a quantitative radioligand assay for CYP2D6 antibody detection. F Hepatol 1998;28: 965-70.

142 Goodman ZD, McNally PR, Davis DR, et al. Autoimmune cholangitis: a variant of primary biliary cirrhosis. Clinicopathologic and serologic correlations in 200 cases. Dig Dis Sci 1995;40:1232-42.

143 Tsuneyama K, Van de Water J, Van Thiel D, et al. Abnormal expression of PDC-E2 on the apical surface of biliary epithelial cells in patients with antimitochondrial antibody-negative primary biliary cirrhosis. Hepatology 1995;22:1440-6.

144 Omagari K, Ikuno N, Matsuo I, et al. Autoimmune cholangitis syndrome with a bias towards primary biliary cirrhosis. Pathology 1996;28:255-8.

145 Nakanuma Y, Harada K, Kaji K, et al. Clinicopathological study of primar biliary cirrhosis negative for antimitochondrial antibodies. Liver 1997;17: 281-7.

146 Kinoshita H, Omagari K, Whittingham S, et al. Autoimmune cholangitis and primary biliary cirrhosis - an autoimmune enigma. Liver 1999;19:1228 .

147 Invernizzi P, Crosignani A, Battezzati PM, et al. Comparison of the clinical features and clinical course of antimitochondrial antibody-positive and -negative primary biliary cirrhosis. Hepatology 1997;25:1090-5.

148 Lacerda MA, Ludwig J, Dickson ER, et al. Antimitochondrial antibodynegative primary biliary cirrhosis. Am F Gastroenterol 1995;90:247-9.

149 Michieletti P, Wanless IR, Katz A, et al. Antimitochondrial antibody negative primary biliary cirrhosis: a distinct syndrome of autoimmune cholangitis. Gut 1994;35:260-5.

150 Taylor SL, Dean PJ, Riely CA. Primary autoimmune cholangitis: an alternative to antimitochondrial antibody-negative primary biliary cirrhosis. $\mathrm{Am}$ F Clin Pathol 1994;18:91-9.

151 Ben-Ari Z, Dhillon AP, Sherlock S. Autoimmune cholangiopathy: part of the spectrum of autoimmune chronic active hepatitis. Hepatology 1993:18: $10-15$.

152 Shimizu Y, Higuchi K, Kashii Y, et al. Clonal accumulation of V $\beta 5.1$-positive cells in the liver of a patient with autoimmune cholangiopathy. Liver 1997;17:7-12. 